\title{
Coal Pillars Safe Mining
}

\author{
Natalya Pirieva ${ }^{1, *}$, and Inna Ermakova ${ }^{2}$ \\ ${ }^{1}$ OJSC «SUEK-Kuzbass», 652507 Vasilyeva street 1, Leninsk-Kuznetsky, Russia \\ ${ }^{2}$ T.F. Gorbachev Kuzbass State Technical University, 650000Vesennyaya street 28, Kemerovo, \\ Russia
}

\begin{abstract}
Safety pillars are the necessary objects for underground mining of coal seams. The having been mines; safety pillars, which include the development workings, lose their purpose. The coal reserves in these pillars are significant and can be mined. However, the pillars have fracture zones in the edges. The size of the fracture zones in the marginal parts of the pillars should be taken into account when choosing a mining system and its parameters. Coal pillar stress-strain analysis was carried out by the finite element method. The developed technique for coal pillar stress-strain analysis takes into account the post-critical strain of the coal seam edge. The reliability of the technique was verified by the experimental method. The calculated and experimental values differ insignificantly. The geomechanical condition of the nine safety pillars in A.D. Ruban mine of OJSC "SUEK-Kuzbass" was studied. The enterprise mines three low dip seams at a depth of up to $290 \mathrm{~m}$. The amount of losses in fracture zones is defined for the pillars, which include slopes and entries. Fracture zones in the pillars were sized taking into account the actual structure of the seam roofs: the depth of bedding, their thickness and strength characteristics. The economic effect of mining of the safety pillars is pre-computed.
\end{abstract}

\section{Introduction}

Underground mining of coal deposits provides for the presence of safety pillars of various purposes: under the surface facilities, stenton walls, to preserve the permanent and development workings, in particular, under slopes and entries. The dimensions of such pillars along the strike reach $300 \mathrm{~m}$, and up the dip - 1000 and more meters. So, in the mines of OJSC "SUEK-Kuzbass" coal reserves in safety pillars of various purposes are 83 million tons, which is $12.5 \%$ of the mineable coal reserves.

Coal reserves in safety pillars have a significant volume, so the rationale of their mining is a topical issue. To solve this problem, difficult mining conditions of pillars should be taken into account. Pillars include development workings and are in the zone of influence of the previously mined blocks. At the first stage of this problem solving, it is necessary to size the failure zones in pillars. This will allow assessing the coal volumes available for mining and reasonable choosing the technology for mining of safety pillars.

The geomechanical state of safety pillars of various purposes was studied by field studies [1-3] and numerical methods [4-14].

The coal failure in the edge of safety pillars occurs under post-critical coal strain. Existing methods for stress-strain analysis of coal pillars and sizing of the failure zones of

\footnotetext{
* Corresponding author: PirievaNN@,suek.ru
} 
their edges do not take into account the post-critical coal strain. In this regard, sizing of the failure zones in safety pillars in flat-lying seam mining with allowance for the post-critical coal strain is a topical task of mining geomechanics.

\section{Methods}

A complex method was used to study the geomechanical state of safety pillars. The stressstrain analysis of coal pillars was carried out by the finite element method. In-situ studies were used to verify the developed technique of numerical calculation.

\section{Results}

The mines of OJSC "SUEK-Kuzbass" mine gently sloping seams. The total coal reserves in safety pillars at the operating mines of OJSC "SUEK-Kuzbass" make up 83,166 thousand tons or $12.5 \%$ of the mineable coal reserves (Table 1 ).

Table 1. Coal reserves at the operating mines of OJSC "SUEK-Kuzbass" as of 01/01/2017.

\begin{tabular}{|l|c|c|}
\hline \multicolumn{1}{|c|}{ Mine } & $\begin{array}{c}\text { Mineable reserves, } \\
\text { thousand tons }\end{array}$ & $\begin{array}{c}\text { Reserves in safety pillars, } \\
\text { thousand tons }\end{array}$ \\
\hline S.M. Kirov mine & 196846 & 8869 \\
\hline A.D. Ruben mine & 10553 & 8439 \\
\hline 7th of November mine & 0 & 223 \\
\hline Polysaevskaya mine & 31232 & 11734 \\
\hline Komsomolets mine & 59467 & 12942 \\
\hline Kotinskaya mine & 50342 & 4919 \\
\hline V.D. Yalevskiy mine & 56040 & 5154 \\
\hline $\begin{array}{l}\text { Taldinskaya Zapadnaya-1 } \\
\text { mine }\end{array}$ & 57470 & 25164 \\
\hline $\begin{array}{l}\text { Taldinskaya Zapadnaya-2 } \\
\text { mine }\end{array}$ & 203324 & 5722 \\
\hline Total & 665274 & 83166 \\
\hline
\end{tabular}

The examples of the mineable safety pillars are given in Figure 1.

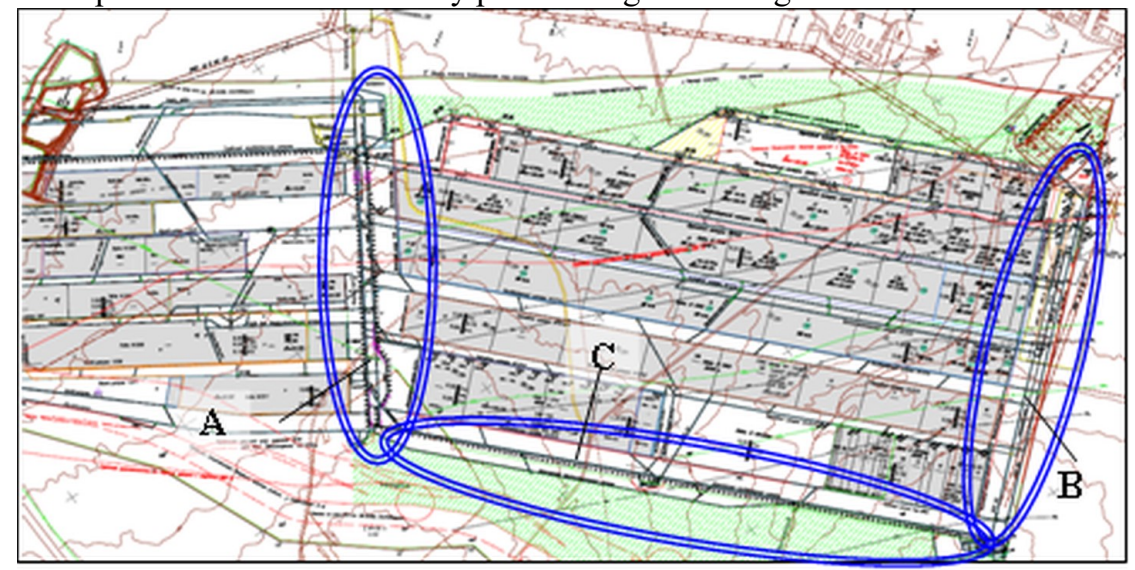

Fig. 1. A plan of mining operations for the Baykaimsky seam in A.D. Ruban mine.

Here is a plan of mining operations for the Baykaimsky seam in A.D. Ruban mine. The mineable safety pillars are circled in blue: the pillars A and B include slopes; the pillar C 
includes entries.To mine safety pillars, it is necessary to know their stress state, which differs significantly from the stress state of seam in virgin rock. The stress level will allow estimating the strength of the pillar edges and the size of the failure zones in them.

To study the condition of the pillars, the methods were developed for sizing of failure zones in safety pillars by the finite element method, taking into account its post-critical strain $[15,16]$.

The experimental verification of the methods for sizing of failure zones in safety pillars was carried out at Nadbaykaimsky seam of A.D. Ruban mine in active longwall face 1210. The bearing pressure distribution was investigated by the method of drill cuttings. Measurement of the volume of sludge drill cuttings is carried out periodically in roadway and belt entry, as well as in longwall face. 6 sludge holes are drilled on each site for it (Figure 2a). The length of holes is $9 \mathrm{~m}$.

a)

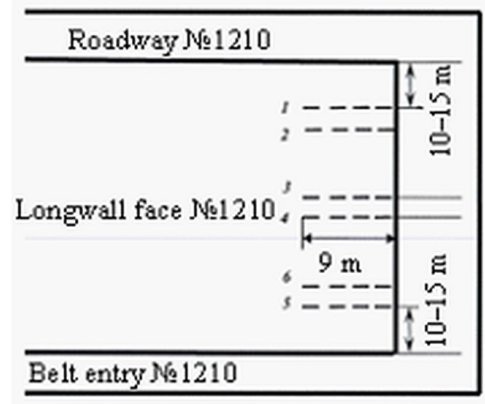

b)

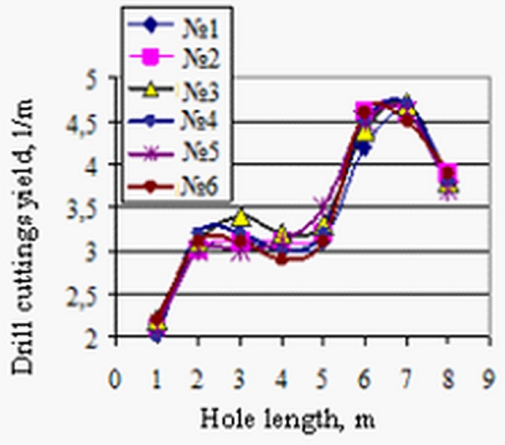

Fig. 2. Sludge drilling and drill cuttings yield chart.

The maximum drill cuttings yield was observed when drilling the 7 th meter of each sludge hole (Figure $2 \mathrm{~b}$ ). A maximum bearing pressure on the seam edge is observed within this interval.

Numerical calculations of the failure zone length (distances to the maximum bearing pressure) in Nadbaykaimsky seam edge, performed for mining and geological conditions of the longwall face № 1210 according to the developed technique, showed a value of $6.5 \mathrm{~m}$.

The value of the maximum bearing pressure from the experimental data was $12.47 \mathrm{MPa}$, and its design value was $14.25 \mathrm{MPa}$. The design and experimental values differ insignificantly. The proposed technique for calculating the length of failure zones in safety pillars is adequate and can be used for calculations.

The developed technique was used to study the geomechanical state of three groups of safety pillars in A.D. Ruban mine of OJSC "SUEK-Kuzbass": 1) mine slope pillars (A); 2) inbye slope pillars (B); 3) ledges (C) (see Figure 1).

Three low dip seams are mined at this mine:

1) seam Polysaevsky-II with depth of $80-124 \mathrm{~m}$, inclination of $6-8^{0}$ and thickness from 4,40 to $5,4 \mathrm{~m}$;

2) seam Nadbaykaimsky with depth of $210-290 \mathrm{~m}$, inclination of $3-70^{\circ}$ and thickness from 2.20 to $2.70 \mathrm{~m}$;

3) seam Baykaimsky with depth of $245-285 \mathrm{~m}$, inclination of 5-120 and thickness from 2.20 to $2.85 \mathrm{~m}$.

The layouts of mining in the vicinity of slope mine roadway and belt entry pillars for three seams are shown in Figure 3.

With increasing depth of working, the length of the safety pillar increases. In particular, the slope pillar along the Baykaimsky seam has a total size of $225 \times 950 \mathrm{~m}$ and estimated coal reserves of 900 thousand tons (see Figure 3c). 
When considering the mutual position of the safety pillars over all three seams, it is possible to distinguish three characteristic sections.

Section 1 - near to the well 11724 . The pillar along Baykaimsky seam on both sides is bordered by the mined out space (see Figure 3c), two slopes are driven in it. Stoping is not provided for Nadbaykaimsky and Polysaevsky-II seams.

Section 2 - near to the well 21567. Two pillars along Nadbaykaimsky and Baykaimsky seams are located one above the other and border on the both sides on the mined out space (see Figure 3b). Three slopes are driven in the pillar along Nadbaykaimsky seam, and two slopes are driven in the pillar along Baykaimsky seam. There are no stoping operations in Polysaevsky-II seam.

Section 3 - near to the well 21577. Three safety pillars along Polysaevsky-II, Nadbaykaimsky and Baykaimsky seams are located one above the other (see Figure 3a). Three slopes were driven in each of them. The pillars along Polysaevsky-II and Baykaimsky seams on both sides border on the mined out space. The pillar along of Nadbaikaimsky seam borders on the mined out space on one side (on the left).

The relative location of the considered pillars, taking into account the planned mining of reserves, is shown in Figure 4.

a)

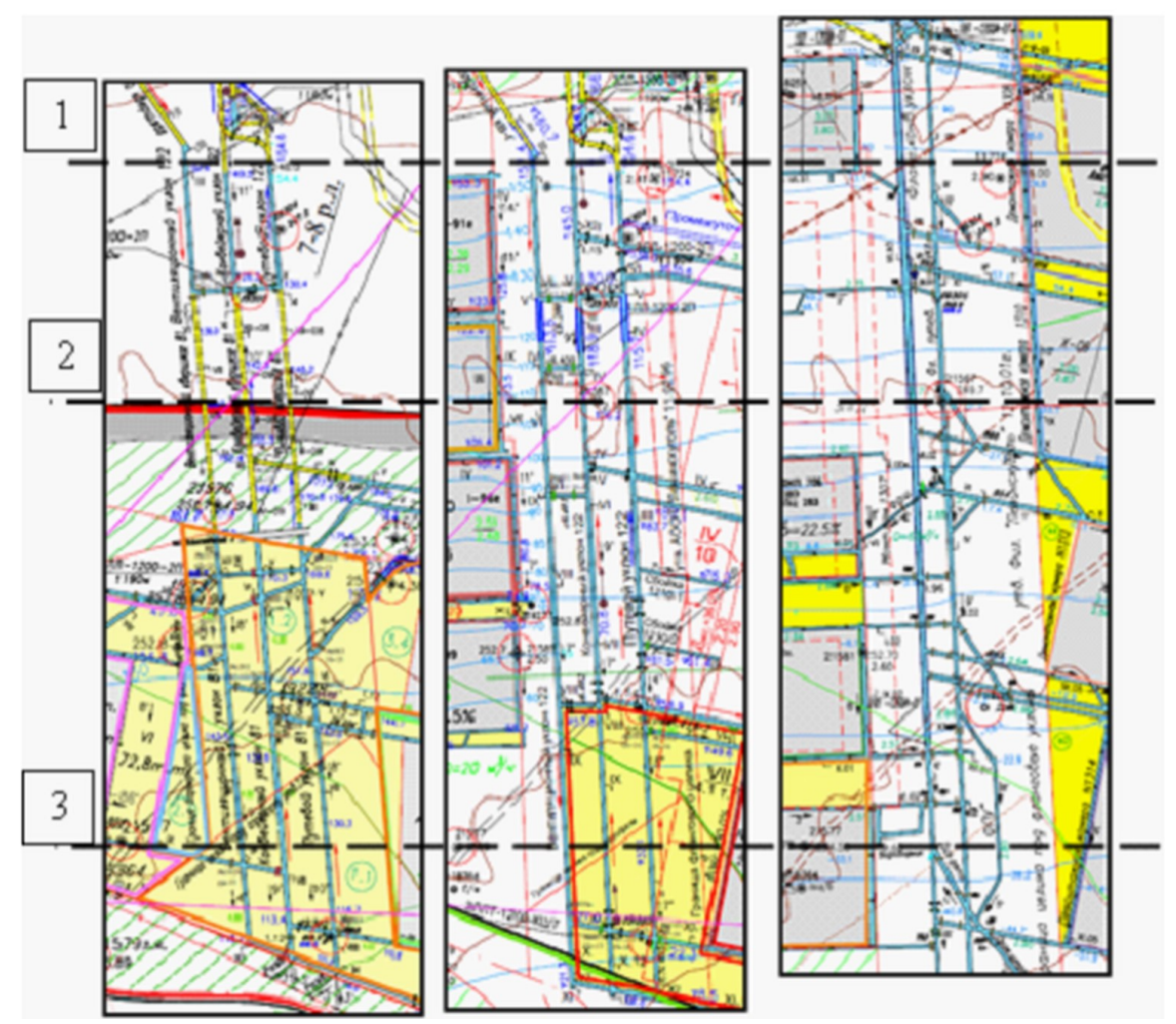

Fig. 3. The layouts of mining in the vicinity of slope pillars for seams: Polysaevsky-II (a), Nadbaykaimsky (b), Baykaimsky (c); 1, 2, 3 - planes of sections near the wells 11724, 21567, 21577 respectively. 


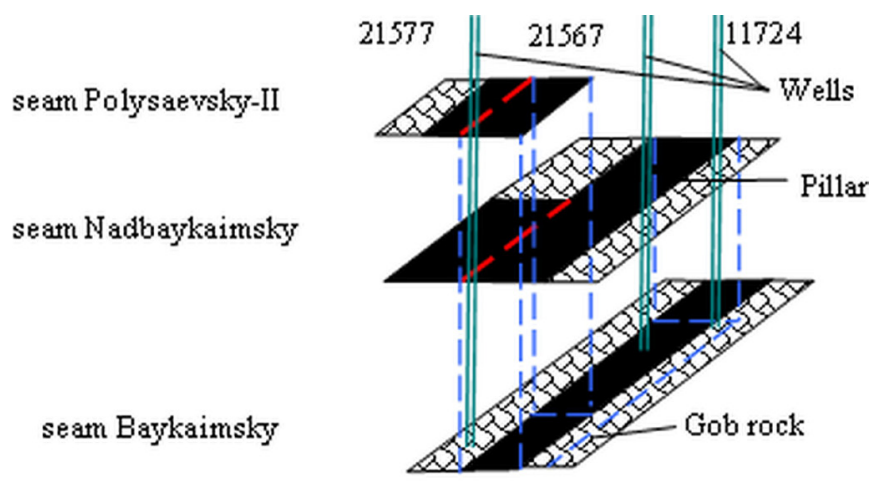

Fig. 4. Position of slope safety pillars along the seams with the indication of wells.

The failure zones in the pillars were sized taking into account the actual structure of the seam roofs: the depth of bedding, their thickness and strength characteristics. This information was obtained for each well.

Computation of the length of the failure zones in the mine and inbye slope safety pillars were carried out in a similar manner.

The condition of the nine safety pillars has been studied. The dimensions of the failure zones in the edges of these pillars were obtained as a result of calculations. Coal reserves, loss in failure zones and the mineable coal reserves are shown in Table 2. Losses in failure zones increase with increasing depth of mining. The average loss for the studied pillars is $9 \%$. The coal reserves in the undisturbed parts of the pillars are 5728 thousand tons.

Table 2. Coal reserves in safety pillars in A.D. Ruban mine.

\begin{tabular}{|c|c|c|c|}
\hline Seam & $\begin{array}{c}\text { Reserves, } \\
\text { thousand } \\
\text { tons }\end{array}$ & $\begin{array}{l}\text { Losses in failure } \\
\quad \text { zones, } \%\end{array}$ & $\begin{array}{l}\text { Reserves including failure } \\
\text { zones, thousand tons }\end{array}$ \\
\hline \multicolumn{4}{|c|}{ 1. Slope pillars } \\
\hline Polysaevsky-II & 442 & 1,3 & 436 \\
\hline Nadbaykaimsky & 658 & 1,6 & 647 \\
\hline Baykaimsky & 900 & 9,4 & 815 \\
\hline \multicolumn{4}{|c|}{ 2. Drainage belt entry pillars } \\
\hline Polysaevsky-II & 825 & 5,5 & 780 \\
\hline Nadbaykaimsky & 825 & 16,3 & 691 \\
\hline Baykaimsky & 825 & 20,0 & 660 \\
\hline \multicolumn{4}{|c|}{ 3. Inbye slope pillars } \\
\hline Polysaevsky-II & 731 & 4,8 & 696 \\
\hline Nadbaykaimsky & 505 & 5,0 & 480 \\
\hline Baykaimsky & 582 & 10,2 & 523 \\
\hline Total & 6293 & 9,0 & 5728 \\
\hline
\end{tabular}

\section{Conclusions}

The results of the calculations make it possible to rationale the choice and parameters of the pillar mining systems. The mining of these pillars will make it possible to obtain an economic effect by saving at tapping and development of new levels. 
The expected economic effect from the introduction of mining of safety pillars in A.D. Ruban mine will be 721.4 million rubles per year. The total annual economic effect for OJSC "SUEK-Kuzbass" will be 10710.27 million rubles.

\section{Reference}

1. B. Yu, Z. Zhang, T. Kuang, J. Liu, Rock Mech. Rock Eng., 49, 3293 (2016)

2. Z. Zhou, L. Chen, X. Cai, B. Shen, J. Zhou, K. Du, Rock Mech. Rock Eng., 51, 1629 (2018)

3. J. Xie, M. Gao, R. Zhang, S. Li, Q. Tan, Z. Qiu, Rock Mech. Rock Eng., 49, 2977 (2016)

4. Sitao Zhu, Yu Feng, Fuxing Jiang, Rock Mech. Rock Eng., 49, 1943 (2016)

5. H. Wang, Y. Jiang, Y. ZhaoJie, Z. Liu, Rock Mech. Rock Eng., 1211, (2016)

6. S. Wencheng, Z. Chunbo, L. Guang, W. Donghui, Coal in the 21st Century: Mining, Processing and Safety, 1 (2016)

7. L. Weitao, S. Wencheng, W. Jianning, Coal in the 21st Century: Mining, Processing and Safety, 1 (2016)

8. J. Yuguo, W. Xianjun, Z. Yongpei, Z. Xiantang, Coal in the 21st Century: Mining, Processing and Safety, 1 (2016)

9. L. Zenghui, K. Tianhe, Ground Pressure and Strata Control, 22(1), 24 (2005)

10. W. Jiachen, P. Weidong, L. Cheng., Journal of Mining \& Safety Engineering, 25(3), 272 (2008)

11. D. V. Griffiths, P. A. Lane, Geotechnique, 49(3), 387 (1999)

12. Z. Peng, X. Ling-Zhi, X. Lun, Journal of China Coal Society, 36(12), 2029 (2012)

13. C. Zhonghui, X. Heping, Chinese Journal of Rock Mechanics and Engineering, 19(4), 436 (2000)

14. S. Rongjun, W. Chunqiu, T. Yunliang, Rock and Soil Mechanics, 28(2), 351 (2007)

15. V. A. Gogolin, Coal in the 21st Century: Mining, Processing and Safety, 86 (2016)

16. I. A. Ermakova, N. N. Pirieva, Coal in the 21st Century: Mining, Processing and Safety, 90 (2016) 